\title{
Improved Two-Phase One-Leg Matrix Converter Using L-C Filter
}

\author{
Roman Koňarik, Branislav Dobrucký and Pavol Štefanec \\ Faculty of Electrical Engineering, University of Žilina, Žilina, Slovak Republic
}

\begin{abstract}
The paper deals with analysis and modelling of a new type of single-phase supplied AC/AC converter with two phase outputs. It consists of one-leg half-bridge matrix converter loaded by the resistive-inductive load in series connection. As harmonic analysis of the voltage of both phases gives very high value of total harmonic distortion (roughly $86 \%$ ) the current waveforms should be improved by using of serial L-C filter - which brings much lesser value acceptable for application. The simulation is resulting in a recommendation for the fair and right design of the converter, and demands to single- or two-phase input supply voltage, respectively, under passive R-L or motoric load.
\end{abstract}

Keywords-matrix converter; one-leg VSI converter; LC resonant filter; half bridge connection; bidirectional switch; modelling; LT spice simulation

\section{INTRODUCTION -BASIC CONNECTION OF ONE-LEG $\mathrm{MXC}$}

Basic scheme of two-phase one-leg MxC converter is derived from VSI adapted scheme [1], [4], Fig. 1.

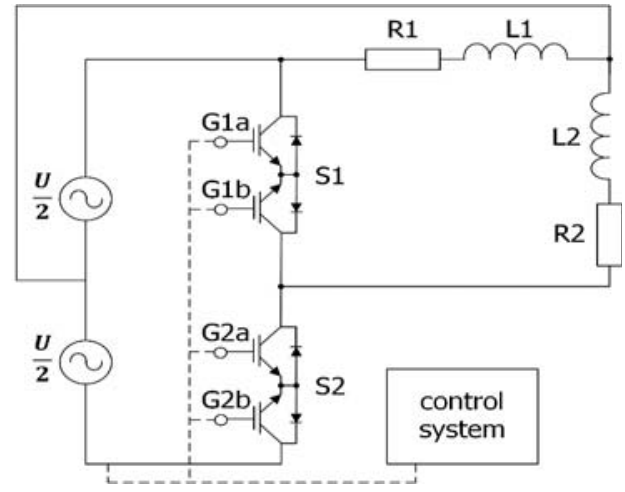

FIGURE I. BASIC SCHEME OF TWO-PHASE ONE-LEG MXC CONVERTER WITH R-L LOAD

Direct connection of the R-L load to power supply auxiliary phase at basis frequency $50 \mathrm{~Hz}$, Figure I. without LC filter and PWM control the following differential equations for current are valid

$$
\begin{gathered}
u(t)=R \cdot i(t)+L \frac{d i(t)}{d t} \text { or } \\
\frac{d i(t)}{d t}=-\frac{1}{\tau} i(t)+\frac{1}{\tau} \frac{u_{a u x}(t)}{R}, \text { respectively. }
\end{gathered}
$$

Using of numerical integration (e.g. Euler explicit method) yields

$$
\mathrm{i}_{\mathrm{k}+1}=\mathrm{i}_{\mathrm{k}}+\Delta \mathrm{T}\left[-\frac{1}{\tau} \mathrm{i}_{\mathrm{n}}+\frac{1}{\tau} \frac{\mathrm{u}_{\mathrm{aux}_{\mathrm{k}}}}{\mathrm{R}}\right]
$$

where

$$
\mathrm{u}_{\mathrm{aux} \mathrm{k}}=\mathrm{u}_{\mathrm{aux}}(\mathrm{k} \cdot \Delta \mathrm{T})
$$

$$
=2 \mathrm{U}_{\mathrm{M}} \operatorname{sign}[\sin (\omega \mathrm{k} \cdot \Delta \mathrm{T})] \operatorname{abs}[\cos (\omega \mathrm{k} \cdot \Delta \mathrm{T})] .
$$

Taking supply voltage between center tape of $\mathrm{MxC}$ and zero point of the motor the calculated current waveform is depicted in Figure II.

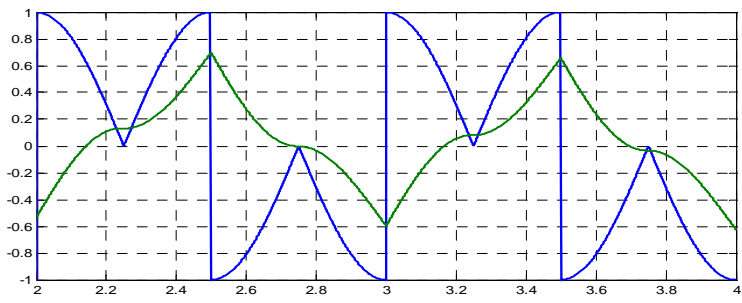

FIGURE II. AUXILIARY PHASE VOLTAGE AND CURRENT WAVEFORMS WITHOUT L-C CIRCUIT AND PWM CONTROL

It's clear that due to strongly non-harmonic voltage ( $86 \%$ [9]) the current time waveform is also non-harmonic. To be the current sinusoidal under any load it should be used some of PWM methods or using L-C filter. Since PWM methods decrease the value of auxiliary phase voltage, it is not suitable to their use for nominal frequency operation - we need full voltage.

Inclusion of L-C circuit into auxiliary phase, tuned on basic frequency, is presented in Figure IIIa. Design of resonant components is described using [12]. We have decided to use the serial resonance L-C filter for fundamental harmonic: Then

$$
\mathrm{L}_{\mathrm{res}}=\frac{\mathrm{U}^{2}}{\omega_{\text {res }} \mathrm{P}} \mathrm{q} ; \quad \mathrm{C}_{\mathrm{res}}=\frac{\mathrm{P}}{\omega_{\text {res }} \mathrm{U}^{2} \mathrm{q}}
$$

where $\mathrm{U}$ is RMS value of phase voltage, $\mathrm{P}$ is $\mathrm{AV}$ value of active power, and $\mathrm{q}$ is design coefficient [12]. Equivalent scheme of auxiliary phase for calculation is given in Figure IIIb.

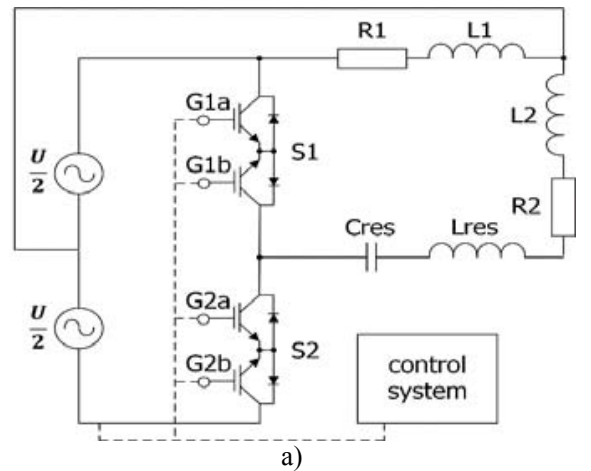




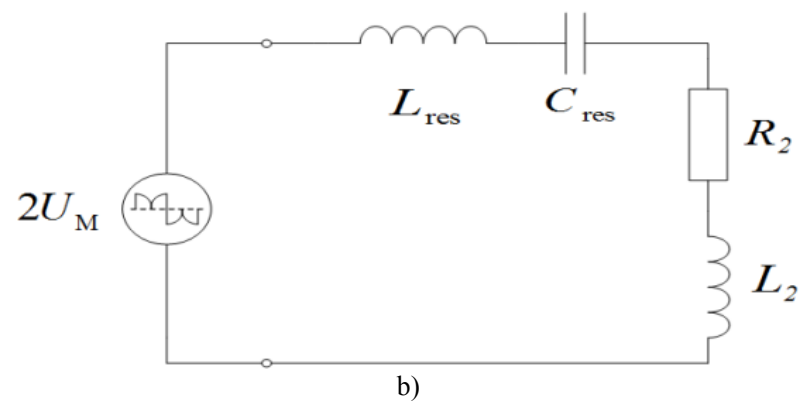

FIGURE III. COMPLETED AUXILIARY PHASE WITH LC RESONANT COMPONENTS A) AND EQUIVALENT SCHEME OF AUXILIARY PHASE FOR CALCULATION B)

System of differential equations for that circuit, similar to previous, gives

$$
\begin{gathered}
\frac{\mathrm{di}_{\mathrm{L}}}{\mathrm{dt}}=-\frac{1}{\tau} \mathrm{i}_{\mathrm{L}}-\frac{1}{\mathrm{~L}} \mathrm{u}_{\mathrm{C}}+\frac{1}{\tau} \frac{\mathrm{U}_{\mathrm{M}}}{\mathrm{R}} \mathrm{u}_{\text {aux }} \\
\frac{\mathrm{du}_{\mathrm{C}}}{\mathrm{dt}}=\frac{1}{\mathrm{C}} \mathrm{i}_{\mathrm{L}}
\end{gathered}
$$

where $\mathrm{L}=\mathrm{L}_{\text {res }}+\mathrm{L}_{\mathrm{aux}}$ and $\mathrm{C}=\mathrm{C}_{\text {res }}$.

Simulation result for auxiliary phase current and capacitor voltage is given in Figure IV.

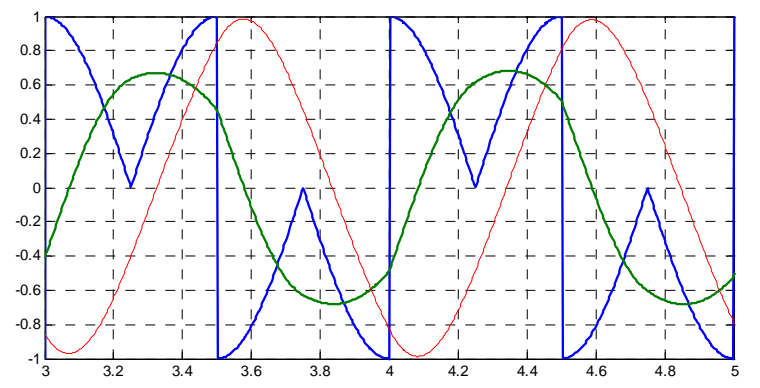

FIGURE IV. SIMULATION RESULT FOR AUXILIARY PHASE CURRENT AND CAPACITOR VOLTAGE, WITH L-C ENHANCED CIRCUIT AT $50 \mathrm{HZ}$

The resulting total harmonic distortion of auxiliary phase current is now much more better (about 4-times lower). Inclusion of L-C circuit into auxiliary phase, tuned on basic frequency

\section{ONE-LEG MXC CONNECTION FOR VARIABLE FREQUENCY}

Basic scheme of $\mathrm{MxC}$ converter for variable frequency regime, derived again from VSI adap-ted scheme [1], [4] is given in Figure Va. The phase shift of auxiliary phase is provided by the capacitor $\mathrm{C}_{\text {aux }}$. vector diagram for auxiliary phase impedances is given in Figure $\mathrm{Vb}$.

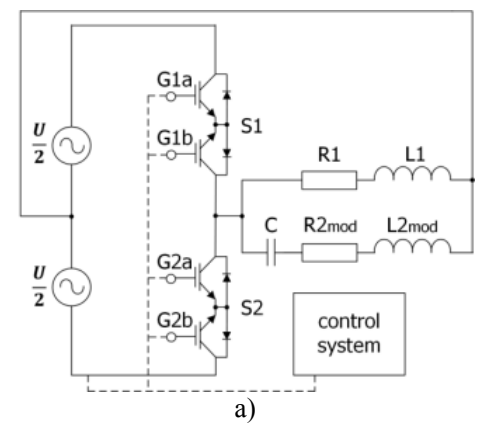

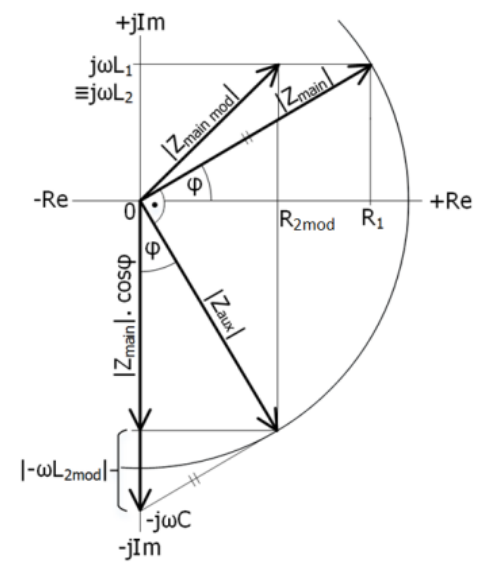

b)

FIGURE V. BASIC SCHEME FOR VARIABLE FREQUENCY OPERATION AND VECTOR DIAGRAM OF AUXILIARY PHASE IMPEDANCES

Calculation $\mathrm{C}_{\mathrm{aux}}$ for geometrical center of frequency band, i.e. $33.33 \mathrm{~Hz}$ : from vector diagram the capacitor value for auxiliary phase can be determined.

$$
\begin{gathered}
\left|Z_{\text {aux }}\right|=\left|Z_{\text {main }}\right| \\
\left|\omega C_{\text {aux }}\right|=\left|Z_{\text {aux }}\right| \cos \varphi+\left|\omega L_{2}\right| \\
C_{\text {aux }}=\frac{\left|Z_{\text {aux }}\right| \cos \varphi+\left|\omega L_{2}\right|}{\omega}
\end{gathered}
$$

There is equality of $\left|\omega L_{2}\right|=\left|\omega L_{1}\right|$ provide the same magnetic flux in both main and auxiliary phases.

Equivalent scheme of auxiliary phase and supply voltage for calculation are given at Figure VI.

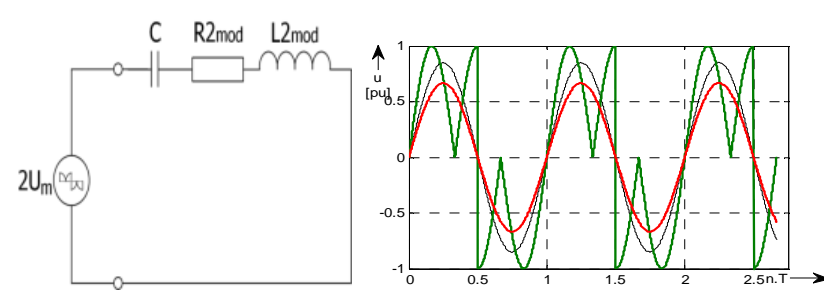

FIGURE VI. EQUIVALENT SCHEME OF AUXILIARY PHASE

AND SUPPLY VOLTAGE FOR CALCULATION AT $33.33 \mathrm{HZ}$

System of differential equations for that circuit, similar to previous, gives

$$
\begin{gathered}
\frac{\mathrm{d} i_{L}}{\mathrm{~d} t}=-\frac{1}{\tau} i_{L}-\frac{1}{L} u_{C}+\frac{1}{\tau} \frac{U_{M}}{R} u_{\text {aux }} \\
\frac{\mathrm{d} u_{C}}{\mathrm{~d} t}=\frac{1}{C} i_{L}
\end{gathered}
$$

where $\mathrm{L}=\mathrm{L}_{\mathrm{aux}}$ and $\mathrm{C}=\mathrm{C}_{\mathrm{aux}}$ and

$$
\begin{gathered}
\mathrm{u}_{\mathrm{aux}}(\mathrm{t})=\operatorname{sign}(\mathrm{U} * \sin (\omega * \mathrm{t}(\mathrm{k}))) * \quad * \operatorname{abs}(\mathrm{U} * \cos (\omega \\
* \mathrm{t}(\mathrm{k})))
\end{gathered}
$$

where coefficient $\frac{3}{2}$ is respecting frequency of $33.33 \mathrm{~Hz}$.

Simulation result for auxiliary phase current at 33.33 $\mathrm{Hz}$ is in Figure VII. 

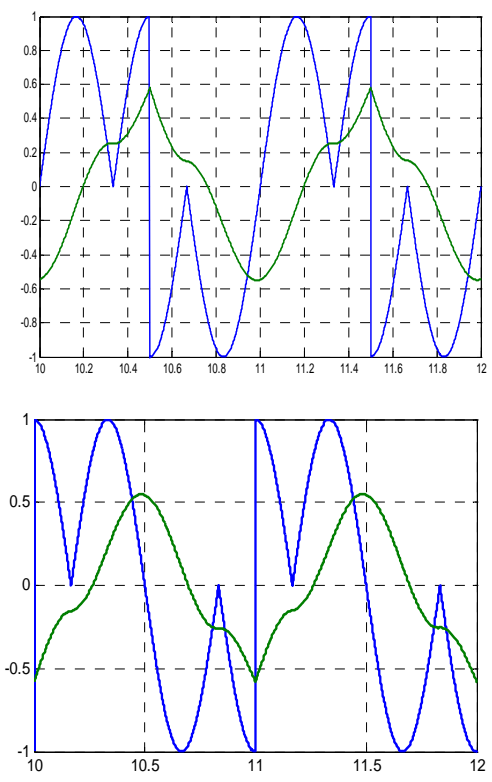

FIGURE VII. MAIN- AND AUXILIARY PHASE CURRENT AT $33.33 \mathrm{HZ}$

As it can be seen auxiliary phase current is again highly non-harmonic with the resulting total harmonic distortion similar as of voltage (roughly $80 \%$ ). So, it is necessary to use inclusion of L-C circuit into auxiliary phase, tuned on geometrical center of frequency band $(33.33 \mathrm{~Hz})$. Moreover, the current wave forms are not symmetrical ones.

\section{USING LC FILTER FOR ENHANCEMENT OF AUXILIARY PHASE CURRENT}

Completing of auxiliary phase by LC resonant circuit tuned on geometric center of frequency range, $33.33 \mathrm{~Hz}$

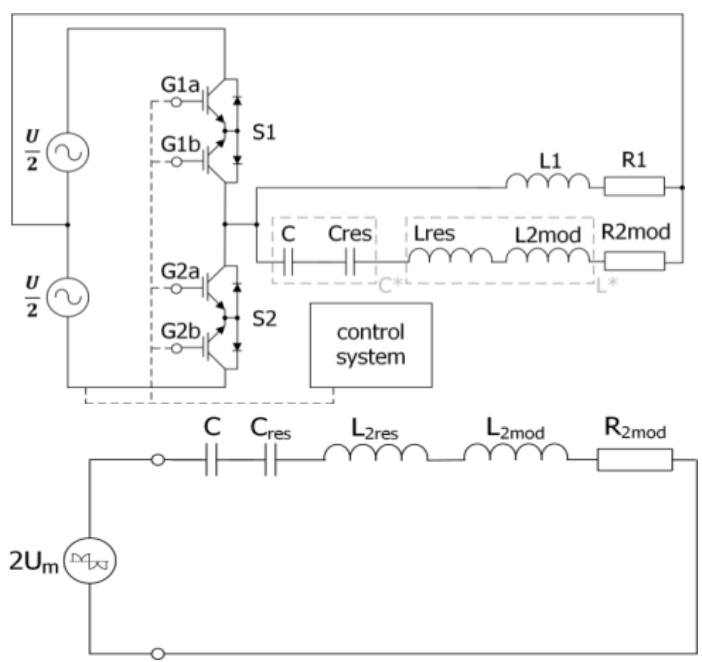

FIGURE VIII. BASIC CIRCUITRY WITH L-C AND EQUIVALENT SCHEME OF AUXILIARY PHASE FOR CALCULATION

Design of resonant components is described as above. We have again decided to use the serial resonance L-C filter tuned on geometrical center of frequency band (66.66 $\mathrm{Hz})$ :

$$
L_{\text {res }}=\frac{U^{2}}{\omega_{\text {res }} P} q ; \quad C_{r e s}=\frac{P}{\omega_{r e s} U^{2} q} .
$$

System of differential equations for that circuit, similar to previous, gives

$$
\begin{gathered}
\frac{\mathrm{d} i_{L}}{\mathrm{~d} t}=-\frac{1}{\tau} i_{L}-\frac{1}{L} u_{C}+\frac{1}{\tau} \frac{U_{M}}{R} u_{\text {aux }} \\
\frac{\mathrm{d} u_{C}}{\mathrm{~d} t}=\frac{1}{C} i_{L}
\end{gathered}
$$

where $\mathrm{L}=\mathrm{L}_{\text {res }}+\mathrm{L}_{\mathrm{aux}}$ and $\mathrm{C}=\mathrm{C}_{\mathrm{res}}+\mathrm{C}_{\mathrm{aux}}$. Simulation results are presented in Fig. 8.

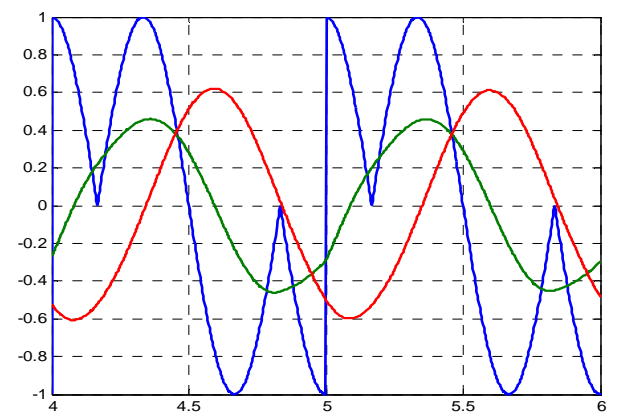

FIGURE IX. AUXILIARY PHASE CURRENT AND CAPACITOR VOLTAGE WITH LC ENHANCED CIRCUIT AT $33.33 \mathrm{HZ}$

The resulting total harmonic distortion of auxiliary phase current is now much more better (about 4-times lower).

\section{VERIFICATION OF OPERATION USING CIRCUIT SiMUlATOR LT SPICE}

Parameters for real circuit: $\mathrm{f}=50 / 33.33 \mathrm{~Hz} ; \mathrm{U}_{\mathrm{rms}}=$ $115 \mathrm{~V} ; \mathrm{P}_{\mathrm{av}}=150 \mathrm{~W} ; \mathrm{R}_{1}=70.53 \Omega ; \mathrm{R}_{2}=52.90 \Omega$; $\mathrm{L}_{1}=170 \mathrm{mH} ; \mathrm{L}_{2}=120 \mathrm{mH} ; \mathrm{C}_{50}=29 \mu \mathrm{F} ; \mathrm{C}_{33}=49.6$ $\mu \mathrm{F} ; \mathrm{q}=2$.

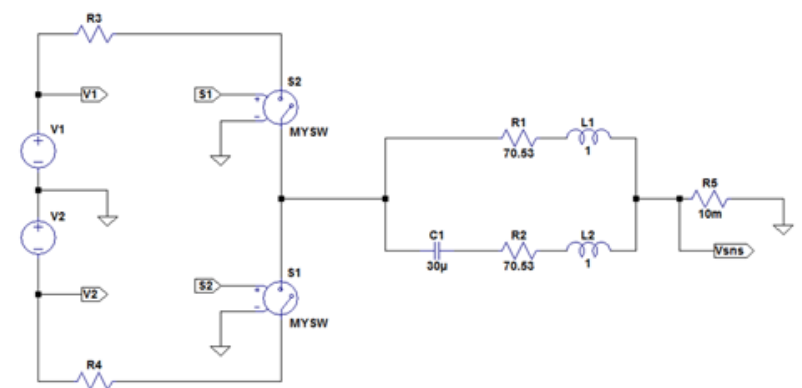

FIGURE X. LT SPICE SCHEME OF ONE-LEG MXC CIRCUITRY (IT CAN BE CHANGE FOR RELATING OPERATION STATE)

Simulation results of voltage and current waveforms are presented for operation at 50 and $33.33 \mathrm{~Hz}$, respectively, in Figure XI and Figure XII.

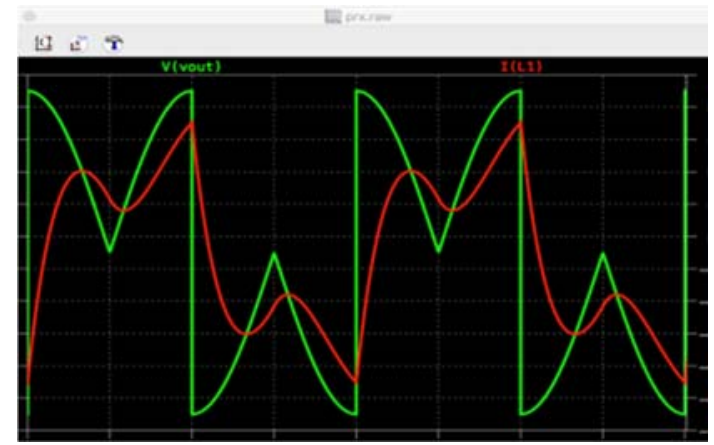

FIGURE XI. VOLTAGE AND CURRENT WAVEFORMS OF AUXILIARY PHASES AT $50 \mathrm{HZ}$ 


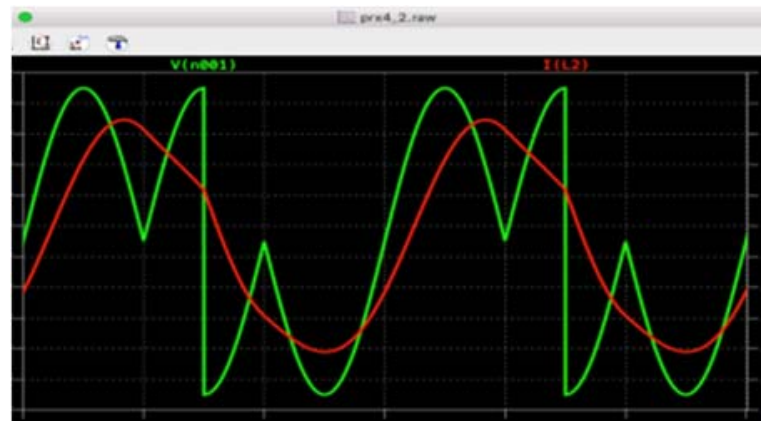

FIGURE XII. VOLTAGE AND CURRENT WAVEFORMS OF AUXILIARY PHASES WITH L-C FILTER AT $33.33 \mathrm{HZ}$

There is possible to use also pulse-with-modulation technique at variable frequency regime, Fig. XIIIb, due to lower voltage needed at lower frequencies as is possible to generate by one-leg matrix converter. Preliminary result is shown in Figure XIV.

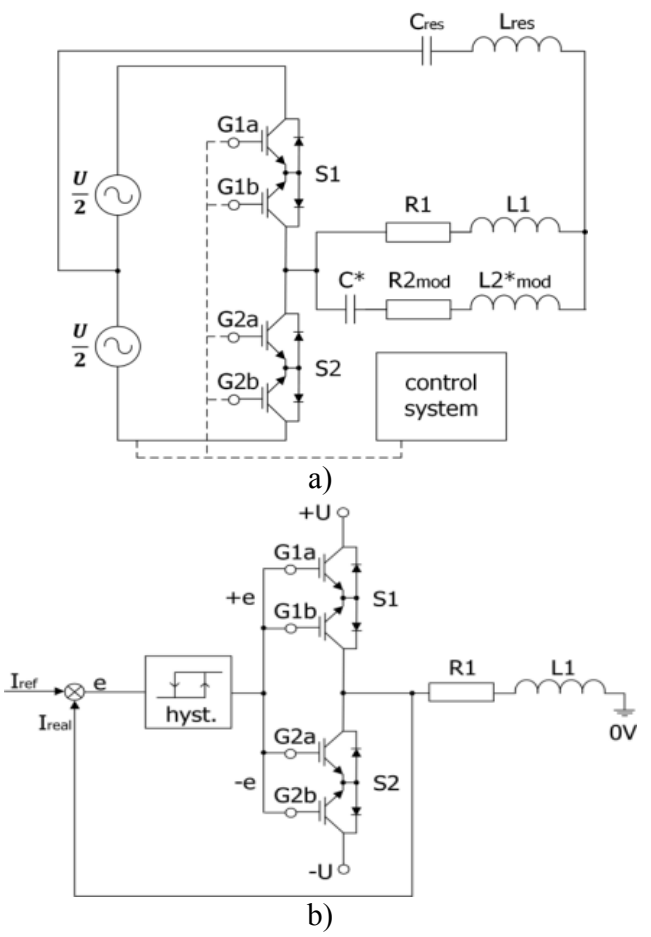

FIGURE XIII. SCHEMATICS OF MXC WITH BOTH L-C FILTERS (A) AND USED CC_PWM FEEDBACK LOOP (B)

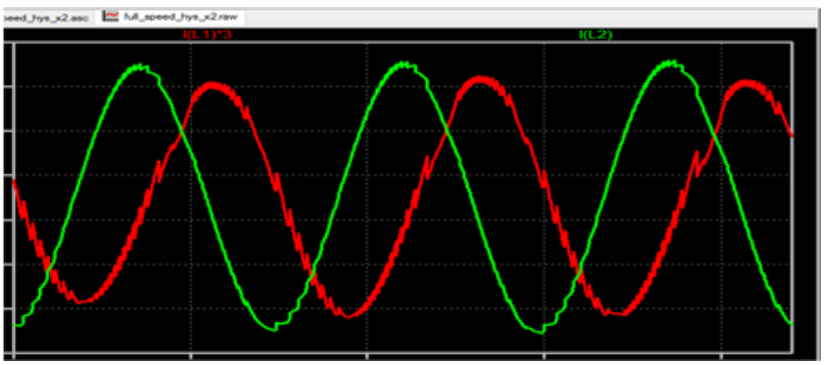

FIGURE XIV. CURRENT WAVEFORMS OF BOTH MAIN-AND AUXILIARY PHASES WITH PWM CONTROL AT VARIABLE FREQUENCY REGIME.

Combining pulse-with modulation technique and using L-C filter circuits will be possible to obtain demanded current waveforms of both main and auxiliary phase. It is necessary for two-phase motoring application.

\section{CONCLUSION}

The paper brings analysis, modelling and computer simulation of an enhanced one-leg matrix converter. Analysis and worked-out simulation experiment results have shown, that use of the LC filter can significantly improve the harmonic of the current waveform in both main and auxiliary windings. This improvement has been show in LT Spice simulation with auxiliary voltage source and simple R-L load and also in MATLAB-Simulink simulation width complete model of one leg $\mathrm{MxC}$ converter. It should be also noticed that the simple L-C resonant tank is always tuned to single frequency only and therefore the right operation of the $\mathrm{MxC}$ converter is also limited to this one frequency.

To eliminate this disadvantage we supposed to use switched capacitor [3], [11] which capacity can be continuously changed and adapted to actual requirement given by operational frequency. The results reached can be served for usage and analysis of systems with two phase AC motor drive.

\section{ACKNOWLEDGEMENT}

The paper was supported from Slovak Grant Agency VEGA by the grant No. 1/0928/15.

\section{REFERENCES}

[1]. M. Chomát, and T. Lipo, “Adjustable-Speed Single-Phase IM Drive with Reduced Number of Switches," IEEE Transactions on Industry Applications, vol. 39, no. 3, pp. 819 - 825, May/June 2003.

[2]. S. Kaščák, T. Laškody, M. Praženica, R. Koňarik, "Current Control Contribution to a Single-Phase Induction Motor Fed by Single-Leg VSI Inverter", accepted paper for ELEKTRO 2016 Int'1 Conference, the High Tatras, Slovakia, May 2016, pp. (TBA).

[3]. Vodovozov, N. Lillo, and Z. Raud, "Single-Phase Electric Drive for Automotive Applications", in Proc. of Int'l Symp. on Power Electronics, Electrical Drives, Automation and Motion SPEEDAM'14, Ischia, 2014, pp. 1293-1298.

[4]. B. Dobrucký, T. Laškody, M. Praženica, "A Novel Supply System for Two- Phase Induction Motor by Single Leg Matrix Converter", Elektronika ir elektrotechnika, ISSN 1392-1215, vol. 21, no. 4, 2015.

[5]. Zuckerberger, D. Weinstock, A. Alexandrovitz, "Single-phase Matrix Converter," IEE Proc. on Electric Power App., Vol. 144(4), pp. 235-240, Jul. 1997.

[6]. S. Jeevananthan, P. Dananjayan, R. Madhavan, "Novel SinglePhase to Single-Phase Cyclo-Conversion Strategies: Mathematical and Simulations Studies", Int'l Journal of Power and Energy Systems, Vol. 27, No. 4, pp. 414-423, 2004.

[7]. B. Dobrucký, P. Špánik, M. Kabašta, ’Power electronic two-phase orthogonal system with HF input and variable output", Electronics and electrical engineering (Elektronika ir elektrotechnika), No. 1 (89), pp. 9-14, 2009.

[8]. P. Chlebiš, P. Šimoník, and M. Kabašta, "The Comparison of Direct and Indirect Matrix Converters “, in Proc. of PIERS Int'l Conf., Cambridge, USA, July 5-8, 2010, pp. 310-313.

[9]. P. Štefanec, B. Dobrucký, "One Leg MxC Analysis and Modelling", 2015 International Conference on Electrical Drives and Power Electronics (EDPE), The High Tatras, 21-23 Sept. 2015, pp. $x x$.

[10]. B. Dobrucký, M. Beňová, M. A. R. Abdamula, S. Kaščák, "Design Analysis of LCTLC Resonant Inverter for Two-Stage 2-Phase Supply System", Automatika - Journal for Control, Measurement, Electronics, Computing and Communications, 2013, vol. 54, no. 3, pp. 299-307.

[11]. Lettenmainer, D. Novotny, and T. A. Lipo, "Single-phase induction motor with an electronically controlled capacitor," IEEE Transactions on Industry Applications, vol. 27, no 1, 1988, pp. 38 43. 